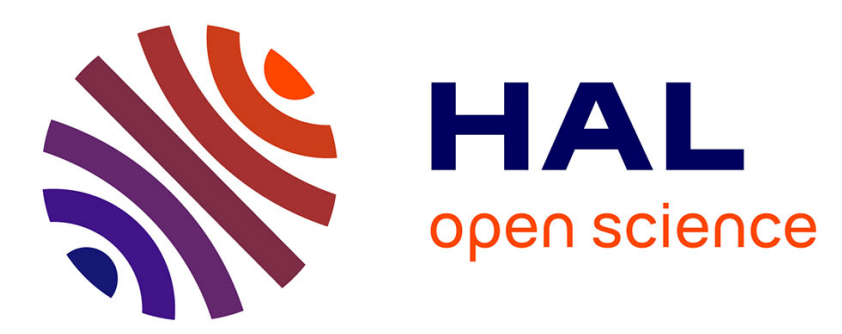

\title{
Damping coefficient estimation of a squeeze-film damper operating in a dual shaft test rig
}

\author{
Claude Gibert, Mikhail Guskov, Lionel Sanchez, Fabrice Thouverez
}

\section{To cite this version:}

Claude Gibert, Mikhail Guskov, Lionel Sanchez, Fabrice Thouverez. Damping coefficient estimation of a squeeze-film damper operating in a dual shaft test rig. Mechanics \& Industry, 2010, 11 (5), pp.297-308. 10.1051/meca/2010067 . hal-02456147

\section{HAL Id: hal-02456147 \\ https://hal.science/hal-02456147}

Submitted on 27 Jan 2020

HAL is a multi-disciplinary open access archive for the deposit and dissemination of scientific research documents, whether they are published or not. The documents may come from teaching and research institutions in France or abroad, or from public or private research centers.
L'archive ouverte pluridisciplinaire HAL, est destinée au dépôt et à la diffusion de documents scientifiques de niveau recherche, publiés ou non, émanant des établissements d'enseignement et de recherche français ou étrangers, des laboratoires publics ou privés. 


\title{
Damping coefficient estimation of a squeeze-film damper operating in a dual shaft test rig
}

\author{
Claude Gibert $^{1}$, Mikhail Guskov $^{1,2, a}$, Lionel Sanchez ${ }^{1}$ and Fabrice Thouverez ${ }^{1}$ \\ 1 Laboratoire de Tribologie et Dynamique des Systèmes, (LTDS, UMR CNRS 5513), Équipe Dynamique des Structures \\ et des Systèmes, École Centrale de Lyon, 36 avenue Guy de Collongue, 69134 Écully Cedex, France \\ 2 Processes and Engineering for Mechanics and Materials Laboratory, (PIMM, UMR CNRS 8006), Structures \\ and System Dynamics group, Arts \& Métiers Paristech, 151 boulevard de l'Hopital, 75013 Paris, France
}

\begin{abstract}
Squeeze film dampers (SFD) are used to reduce dynamical loads in rotating machinery or to improve their performances in numerous industrial applications. The present paper considers the response of a dual shaft system with a SFD mounted on one of its bearings. The study is concerned with the overall system's dynamics in presence of a sealed SFD bearing with a lateral feeding groove and more specifically with the characterization of such damper in operational conditions. The design characteristics of the SFD are based on the linear approximation and the optimization w.r.t. sensitivity of appropriate eigenmodes of a numerical model of the dual shaft test rig. In order to gain more insight into the SFD operation, the experimental kinematic and pressure measurements data are processed within a numerical model of the fluid film using the short bearing approximation of the Reynolds equation and taking into account the flow into the groove. The work holds for low Reynolds number and completely sealed SFD were vapour cavitation is completely absent.
\end{abstract}

Key words: Rotor dynamics / multi-shaft / critical speed / squeeze film damper / experiment

Résumé - Estimation du coefficient d'amortissement d'un squeeze-film opérant dans un système bi-rotor. Les amortisseurs à film écrasé (ou SFD pour squeeze-film damper) sont employés afin de réduire les sollicitations ou d'améliorer la stabilité des machines tournantes dans différents domaines industriels. La présente étude concerne le comportement d'un système bi-rotor en présence d'un SFD installé sur l'un des paliers. On s'intéresse à la dynamique d'ensemble en présence d'un SFD étanche muni d'une gorge d'alimentation latérale et plus particulièrement à la caractérisation d'un tel palier en fonctionnement. Les paramètres de l'amortisseur SFD ont été définis à partir de sa caractéristique théorique et de la courbe de sensibilité à l'amortissement d'un modèle numérique du bi-rotor. Afin de valider l'efficacité du film amortisseur sur la dynamique d'ensemble du système, les données expérimentales au niveau du palier sont injectées dans le modèle numérique de palier basé sur l'approxmation palier court de l'équation de Reynolds avec une prise en compte de l'écoulement dans la gorge d'alimentation. L'étude suppose que le nombre de Reynolds est faible et que le SFD complètement étanche est exempt de cavitation de vapeur.

Mots clés : Dynamique des machines tournantes / multi-rotors / vitesse critique / amortisseur à film écrasé / expérience

\section{Introduction}

Modern trends of development in turbomachinery are to increase the power/weight ratio, especially in aircraft engines. This brings about higher loads in structural parts and a necessity to develop vibration reduction methods but also to increase systems' stability. One of technological solution providing a dissipation source

\footnotetext{
${ }^{a}$ Corresponding author: mikhail.guskov@paris.ensam.fr
}

on the statoric part of a rotating machine is to use a squeeze film damper (SFD). The SFD technology is developed since several decades [1-4]. It involves several physical phenomena (Poiseuille flow, cavitation, thermal effects, inertia effects, boundary conditions) affecting the device's operational dissipation properties. Several SFD models are available nowadays for the engineering design and characterization, allowing different complexity levels $[4,5]$. However, it is crucial to control the adjustment 


\section{Nomenclature}

\begin{tabular}{|c|c|}
\hline$C$ & radial clearance of the $\mathrm{SFD}, \mathrm{m}$; \\
\hline$C_{\mathrm{g}}$ & radial depth of the groove, $\mathrm{m}$; \\
\hline$C_{\mathrm{v}}$ & SFD viscous damping coefficient, N.s.m ${ }^{-1}$; \\
\hline$C_{\mathrm{vr}}, C_{\mathrm{vt}}$ & estimated viscous damping coefficient, N.s.m ${ }^{-1}$; \\
\hline $\mathrm{d} \theta$ & infinitely small increment of the variable $\theta, \operatorname{rad}$; \\
\hline$D_{\mathrm{H}}$ & hydraulic diameter, m; \\
\hline$(e, \phi)$ & polar coordinates of point $\mathrm{O}^{\prime} ; \mathrm{m}, \mathrm{rad}$; \\
\hline$f_{\mathrm{r}}, f_{\mathrm{t}}$ & radial and tangential component of SFD force, $\mathrm{N}$; \\
\hline$g_{\mathrm{r}}, g_{\mathrm{t}}$ & radial and tangential component of the groove force, $\mathrm{N}$; \\
\hline$h(\theta)$ & squeeze-film thickness, m; \\
\hline HP & high pressure (rotor); \\
\hline$i$ & index for pressure signals; \\
\hline i & imaginary unit; \\
\hline$L$ & axial length of SFD, m; \\
\hline$L_{\mathrm{g}}$ & axial length of the groove, $\mathrm{m}$; \\
\hline LP & low pressure (rotor); \\
\hline LVDT & linear variable differential transformer; \\
\hline $\mathrm{O}$ & center of the SFD outer ring; \\
\hline$(\mathrm{O} ; X, Y, Z)$ & Cartesian frame attached to the SFD outer ring; \\
\hline $\mathrm{O}^{\prime}$ & center of the SFD inner ring; \\
\hline$p(\theta, z)$ & pressure distribution in the film land, bar; \\
\hline$p_{i}$ & pressure simulated at location Pri, bar; \\
\hline$p_{\mathrm{g}}(\theta)$ & pressure distribution in the groove, bar; \\
\hline $\operatorname{Pr} i$ & $i$ th pressure sensor; \\
\hline$P_{\mathrm{g}}$ & feeding pressure of the SFD, bar; \\
\hline$P_{i}$ & pressure measured at location Pri, bar; \\
\hline$q_{1}$ & local flow out of the SFD land to the groove, $\mathrm{m}^{2} . \mathrm{s}^{-1}$; \\
\hline$Q_{\mathrm{g}}$ & circumferential flow distribution in the groove, $\mathrm{m}^{3} \cdot \mathrm{s}^{-1}$; \\
\hline$R$ & SFD journal radius, m; \\
\hline$S_{\text {LVDT }}$ & LVDT sensor sensitivity, mm. $\mathrm{V}^{-1}$; \\
\hline SFD & squeeze-film damper; \\
\hline$t$ & time, $\mathrm{s}$ \\
\hline$T$ & temperature measured at the $\mathrm{SFD}$ outer ring, ${ }^{\circ} \mathrm{C}$ \\
\hline $\begin{array}{l}V_{1}, V_{2}, V_{10}, V_{20} \\
\left(X_{e}, Y_{e}\right)\end{array}$ & $\begin{array}{l}\text { voltage signal returned by the instrumentation of the LVDT sensors, Volt; } \\
\text { position of the point } \mathrm{O}^{\prime} \text { in }(\mathrm{O} ; X, Y, Z), \mathrm{m} \text {; }\end{array}$ \\
\hline$\left(\dot{X}_{e}, \dot{Y}_{e}\right)$ & velocity of the point $\mathrm{O}^{\prime}$ in $(\mathrm{O} ; X, Y, Z), \mathrm{m}_{\mathrm{s}} \mathrm{s}^{-1}$ \\
\hline$\varepsilon$ & eccentricity ratio of the journal $(=e / C)$ \\
\hline$\eta$ & constant speed ratio between rotation speed of LP and HP; \\
\hline$\gamma$ & updating parameter of the hydraulic diameter; \\
\hline$\mu$ & dynamic viscosity of the SFD fluid, Pa.s; \\
\hline$\theta$ & circumferential angular coordinate on the inner ring, rad; \\
\hline$\hat{\theta}$ & circumferential angular coordinate on the outer ring, rad; \\
\hline$\tau_{\mathrm{HP}}$ & period of revolution of the HP rotor, s; \\
\hline$\phi$ & attitude angle of the journal, rad; \\
\hline$\omega$ & spin rate, $\operatorname{rad} . \mathrm{s}^{-1}$ \\
\hline$i$ & index for pressure measurment locations. \\
\hline
\end{tabular}

of the SFD bearings mechanical impedance to the global vibration response of the dynamical system. An extensive general historic overview of the development and usage of squeeze-film devices is given in [6].

Some turbomachinery equipments are characterized by a high pressure variation, which justifies the use of several spools, each having its rotor spinning at the optimal rate. Some of them have an intershaft bearings in order to reduce the stator weight. This design solution leads to a dynamic coupling of the spools so that the unbalance of each rotor involves a global response of the structure.

Several studies of SFD-equipped machines in multishaft context exist. In 1991, El-Shafei [7] studied theoretically an intershaft SFD and has come to the conclusion 


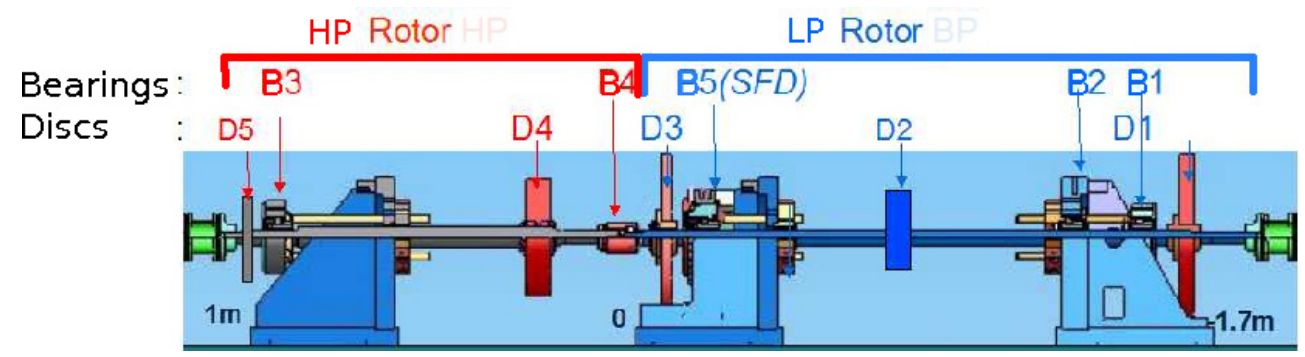

Fig. 1. CAD overall view of the dual shaft test rig. Elements: $\mathrm{D} i-\operatorname{discs}, \mathrm{B} i$ - bearings.

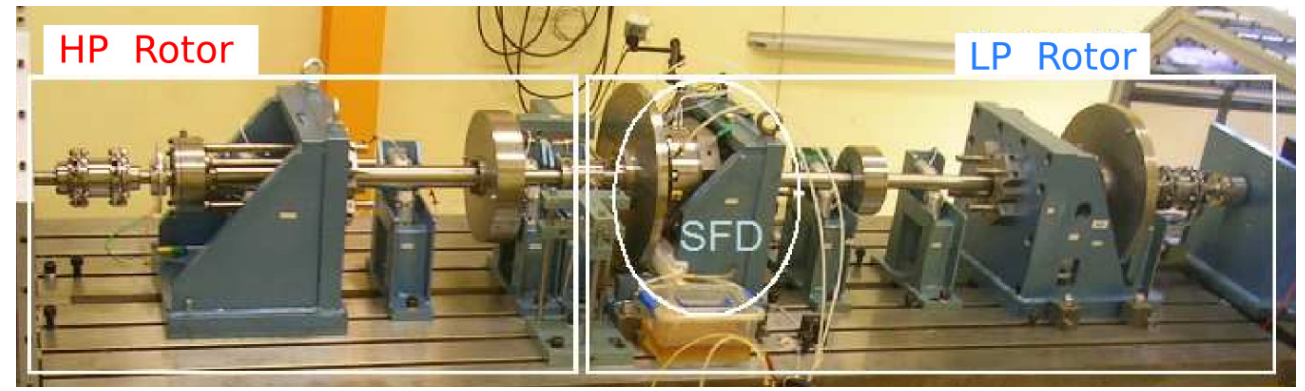

Fig. 2. Global test rig view.

that it becomes unstable when the regime exceeds the critical speed w.r.t. the rotor the SFD is mounted on. In 2007, Gupta et al. [8] presented a numerical and experimental study of a small-scale dual-shaft test bench with an inter-shaft SFD. It has been observed that an optimal value of clearance can be determined in order to suppress a given eigenmode of the structure. In 2008, Defaye [4] explored several inter-shaft squeeze film configurations. In 2009, Delgado et al. [9] have studied the characteristics of a SFD test rig undergoing multi-frequency, non-circular motions.

The present study's subject is a dual shaft test rig designed at École Centrale de Lyon [10-12]. One of its bearings is equipped with an SFD. This machine features multiple critical speeds with respect to each rotor in its operational range.

The article is composed as follows. Firstly, an overall description of the test rig is provided and its dynamical behavior is presented. Secondly, the introduction of SFD is considered and the squeeze film forces modeling approach is shown. Finally, the measurements results are presented and analyzed.

\section{Test rig description}

The rig comprises two rotors 1.7 and $1 \mathrm{~m}$ long and weighing 120 and $60 \mathrm{~kg}$ respectively, as shown in Figure 1. These two rotors are supported by 5 rolling element bearings including one intershaft bearing and three flexibly supported bearings. The SFD is installed at the bearing B5. The flexible bearings supports at B1, B3, B5 are constituted each one of four elastic beams as seen in Figures 1 and 2. In the particular case of B5 the beams play the role of a centralising spring which prevents the journal from rotating as well. The rig's overall architecture is analogous to that of some dual shaft turbofan aircraft engines having a low pressure spool (LP, rotor 1) and a high pressure one (HP, rotor 2). Each rotor is driven by its own electric motor, their rotations are decoupled due to the intershaft bearing B4. A particularity of the rig is that the parts representing the casing are relatively stiff: see the pedestals (in blue) in Figures 1 and 2 to which flexible bearing supports are clamped. Then, the transverse vibrations of the two rotors are essentially coupled by the intershaft bearing $\mathrm{B} 4$. The ratio between the rotation speeds of the shafts is kept constant and equals $\eta=2.778$. The rotors can operate in co-rotating and counter-rotating mode.

The modal analysis of the rig yields 4 to 5 forward critical speeds in the operation range (depending on coor counter rotation) $[10,11]$. Owing to different rotation speeds, unbalance of each rotor excite different amount of eigenmodes: the HP rotor goes through 4 to 5 modes while the LP rotor reaches only the first mode's forward critical speed.

By the following, two modes, namely the 1st and the 4th, will be considered, because they involve relatively high amplitudes in the vicinity of the fifth bearing and thus are primary target for an SFD at that location [12].

Global test rig view is given in Figure 2. The two shafts, bearing supports and discs positions as well as orbit measuring stations are shown.

\section{Squeeze-film Damper description}

\subsection{Mechanical arrangement}

The detail of the squeeze film damper is shown in Figure 3 and a cross section of the bearing is seen in 


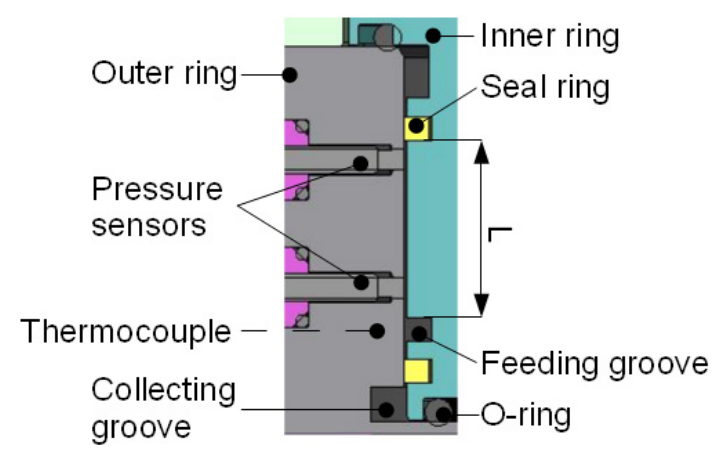

Fig. 3. Close-up view of the SFD, axial cross-section.

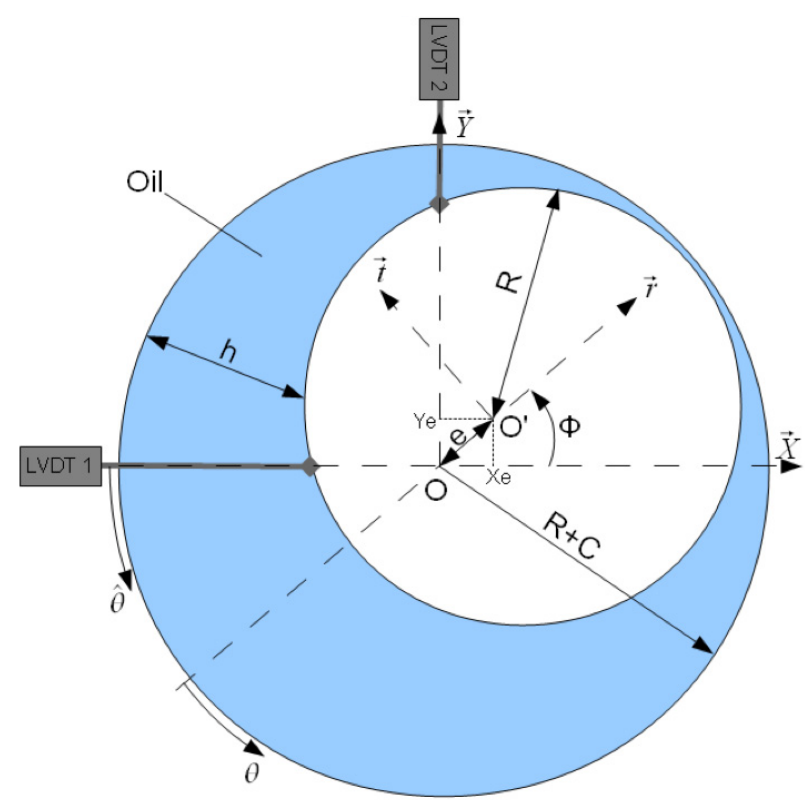

Fig. 4. Schematic of the SFD - transverse cross-section.

Figure 4. The damper journal has a radius $(R)$ equal to $92 \mathrm{~mm}$ and an axial length $(L)$ equal to $26 \mathrm{~mm}$. The radial clearance $(C)$ is $0.250 \mathrm{~mm}$. The Cartesian frame $(\mathrm{O} ; X, Y, Z)$ is attached to the outer ring centered at the point $\mathrm{O}$. The position of $\mathrm{O}^{\prime}$, the inner ring (journal) center is described by $\left(X_{e}, Y_{e}\right)$ or by polar coordinates $(e, \phi)$ with $e$ the distance between the two centers and $\phi$ the angle between the $X$ axis and the line of centers $(\mathrm{O}$, $\left.\mathrm{O}^{\prime}\right)$. The SFD is sealed by means of two split piston ring seals. The film land $(L)$ is delimited by one of them on one side and by a circumferential lateral feeding groove on the other side. The axial length of the groove $\left(L_{\mathrm{g}}\right)$ is $3.5 \mathrm{~mm}$ and its depth $\left(C_{\mathrm{g}}\right)$ is $3.8 \mathrm{~mm}$. The fluid is discharged through the two piston rings into two collecting grooves at ambient pressure before being drained back to the tank. The global flow through the SFD was estimated using a flowmeter during operation and found to be less than 0.4 L.min ${ }^{-1}$. The two o-rings seen in Figure 3 are used to avoid too much oil to get out of the collecting grooves and are only slightly compressed. It has been checked experimentally that they produce no significant effect on the dynamic responses.
The fluid used is ESSO 2380 turbo oil the nominal kinematic viscosity of which is $24 \mathrm{cSt}$ at $40{ }^{\circ} \mathrm{C}$ and $5 \mathrm{cSt}$ at $100{ }^{\circ} \mathrm{C}$ and the density of which is $975 \mathrm{~kg} \cdot \mathrm{m}^{-3}$.

The mounting of two pressure sensors is shown in Figure 3 . They are radially positioned in order to minimize the local perturbation (estimated at about $10 \mu \mathrm{m}$ ) brought to the geometry of the concave cylindrical outer ring surface while preventing from any risk of contact with the inner ring. A total of six strain gauge pressure sensors are located as shown in Figure 5. The sensor $\operatorname{Pr}_{1}$ is located facing the feeding groove, $\operatorname{Pr}_{2}$ and $\operatorname{Pr}_{5}$ are installed circumferentially $90^{\circ}$ apart at the same axial location near the piston ring seal, $\operatorname{Pr}_{3}$ and $\operatorname{Pr}_{6}$ are $180^{\circ}$ apart in the middle of the film land and $\mathrm{Pr}_{4}$ is at the same circumferential location than $\mathrm{Pr}_{2}$ near the feeding groove. The film temperature is measured at two locations close to the film land with thermocouples located in the outer ring. Position of inlets and draining points are also indicated.

The journal orbital motion is measured by means of two identical LVDT sensors with their core mounted on the journal and the coil on the outer ring close to the SFD film (see LVDT1 and LVDT2 in Fig. 4) mounted 90 degrees apart. The inner and outer rings of the SFD are mechanically centered at rest. The eccentricity at rest is verified by means of a depth gauge used at different stations around the rings. As the signals from LVDT1 and LVDT2 increase when the local film thickness at location $\mathrm{Pr}_{5}$ (respectively $\mathrm{Pr}_{2}$ ) increase, the coordinates of $\mathrm{O}^{\prime}$ in the $(\mathrm{O} ; X, Y, Z)$ frame are derived from LVDT using the following expressions:

$$
X_{e}=\left(V_{1}-V_{10}\right) S_{\mathrm{LVDT}} \quad Y_{e}=-\left(V_{2}-V_{20}\right) S_{\mathrm{LVDT}}
$$

where $S_{\mathrm{LVDT}}$ is the sensor sensitivity, $V_{1}, V_{2}$, the voltage signal returned by the instrumentation of the displacement sensors and $V_{10}, V_{20}$ are values corresponding to the bearing being centered $(\epsilon \approx 0)$. The pressure measured at location Pri will be written $P_{i}$.

\section{Experimental results}

\subsection{Overall dual shaft test rig dynamics}

The dynamic behavior of the dual-rotor system in each one of its different configurations (with or without SFD) is characterized by means of its unbalanced responses for known unbalance mass added to the disks.

The response linearity w.r.t. unbalance is checked and it is possible to identify the system damping in that configuration.

As presented in [12], the introduction of the damper at bearing B5, represented by a viscous damper of coefficient $C_{\mathrm{v}}$, has a major influence on the modes targeted during the design, that is to say the modes \#1 and \#4. In particular, the sensitivity of the mode \#1 response w.r.t. unbalance added on HP rotor was reduced by 2 to 3 depending on co- or counter-rotating operation. The fourth mode shape has undergone a slight evolution. This change is accompanied by a frequency shift of the peak and an 


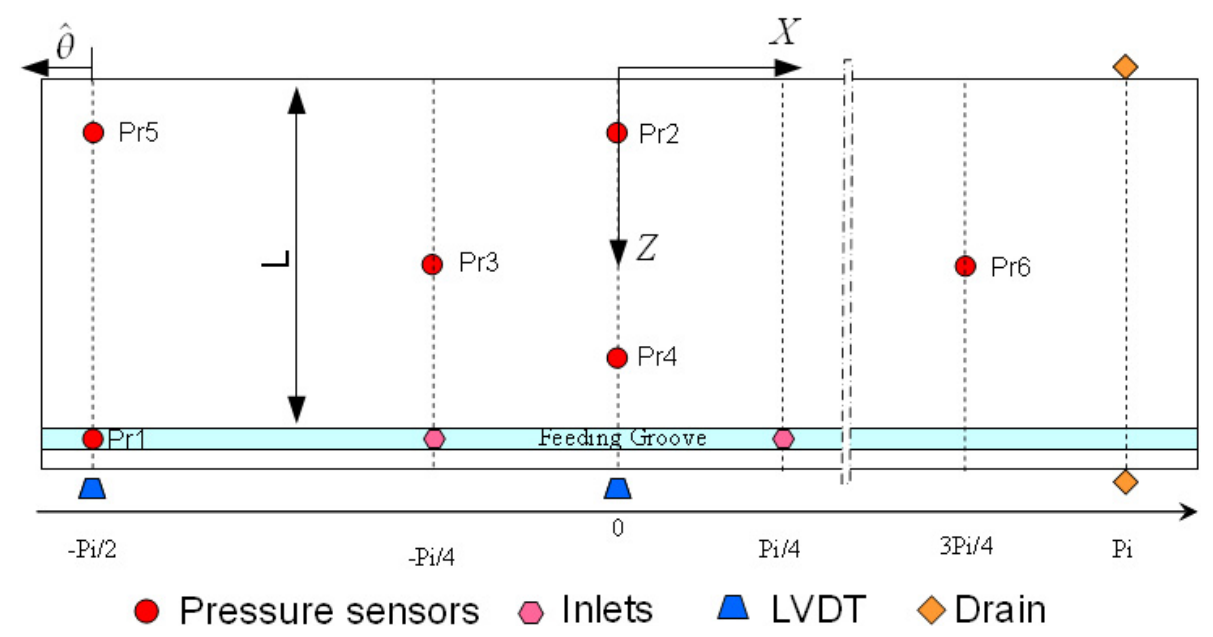

Fig. 5. Instrumentation map of the SFD.

increase in response magnitude. The latter could be interpreted as the locking of bearing 5 by an impedance exceeding its optimum value.

The damper viscous coefficient $C_{\mathrm{v}}$ identification is done by comparing experimental measurements with numerical simulation of responses obtained with different values of this parameter. The best values for the damper viscous coefficient are comprised between 60 and 80 kN s.m ${ }^{-1}$, see Figure 6 .

We note that these values are significantly different despite the nearly linear behavior of the whole system and that the second value is relatively high. Several hypothesis could be tested in order to try to analyze this, such as for instance, the presence of an auxiliary unwanted interaction between journal and bearing support in SFD (possibly involving piston ring seal) or small discrepancies between numerical model and actual structure which could influence results identification.

\subsection{Qualitative analysis of experimental data in the SFD}

Two different running conditions are also analyzed herein. The 1st one corresponds to the first critical speed at a frequency of $28.7 \mathrm{~Hz}$ (corresponding to $\approx 10 \mathrm{~Hz}$ for the LP rotor) and the second one to the 4 th critical speed at $77.6 \mathrm{~Hz}(\approx 28 \mathrm{~Hz}$ for the LP rotor). The two rotors are co-rotative and running counter clockwise in the $(\mathrm{O} ; X$, $Y, Z)$ frame of Figure 4.

Figure 7 shows the dynamic part of the pressure is sensors at $\operatorname{Pr}_{1}$ to $\operatorname{Pr}_{6}$, with respect to time (s) at the first critical speed together with the displacement measured by the LVDT sensors. Relatively low maxima of pressure (approximately 0.5 bar) are observed. Note that in accordance with the literature e.g. $[13,14]$, for an open and a partially sealed SFDs respectively, it is observed that the groove pressure (at $\operatorname{Pr}_{1}$ ) may have significant variations. Given the pressure sensors disposition, the order of time arrival of maxima agrees with a precession from $\mathrm{Pr}_{2}$ to $\mathrm{Pr}_{5}$, the latter lagging a fourth of the HP period
$\left(\tau_{\mathrm{HP}}=0.035 \mathrm{~ms}\right)$ which is in accordance with the fact that the main excitation is introduced by the HP rotor exciting a forward mode. One can check that $P_{5}$ and $P_{1}$ are in phase as for $P_{2}$ and $P_{4}$ which are at a same circumferential locations. Also, $P_{5}$ and $P_{2}$ have nearly the same amplitude whereas $P_{4}$ which is closer to the groove has lower level. $P_{6}$ has the same amplitude as $P_{3}$ and appears delayed by half a period of HP. Interestingly, some higher frequency components are detected in pressure signals (and almost undetectable by displacement sensors) which effect may be attributed to the roller or ball bearings. Apart this the dynamic pressure signals are close to sinusoid.

The journal orbit w.r.t. the outer ring during six revolutions of the HP rotor can be seen in Figure 8, represented in the $(\mathrm{O}, X, Y)$ plane. This is close to a circle with a radius on the order of $20 \mu \mathrm{m}$ (represented in the same diagram) which corresponds to a small eccentricity ratio of $\varepsilon=0.08$. The orbit is not periodic due to the presence of two main frequencies not integer-related which depend on the two rotational speeds (LP \& HP) as the two rotors provide excitation by their unbalances. This orbit is described by the coordinates $\left(X_{e}(t), Y_{e}(t)\right)$ of the journal which are used for calculating the pressure distribution as it is shown below.

In the case of the 4th critical speed, all signals measured in the SFD (Fig. 9) contain one main frequency component at $\approx 78 \mathrm{~Hz}$, superimposed with a lower one at $28 \mathrm{~Hz}$ and again some higher frequency components that can be distinguished particularly on the pressure signals. The trajectory is shown on (Fig. 10) and compared to a circle with a radius $e=45 \mu \mathrm{m}(\varepsilon \approx 0.18)$. Considering the pressure responses, globally speaking and not astonishingly given the rotating speed and the amplitude of displacements, levels about six times higher (up to 3 bar) are observed compared to the first case (for nearly the same temperature conditions and therfore the same fluid viscosity). Although, it should be reminded that the amplitude of the dynamic pressure is still significantly lower than the static feeding pressure $\left(P_{\mathrm{g}}=6\right.$ bar $)$ limiting this way any cavitation effect. Again, a fluctuation is observed 


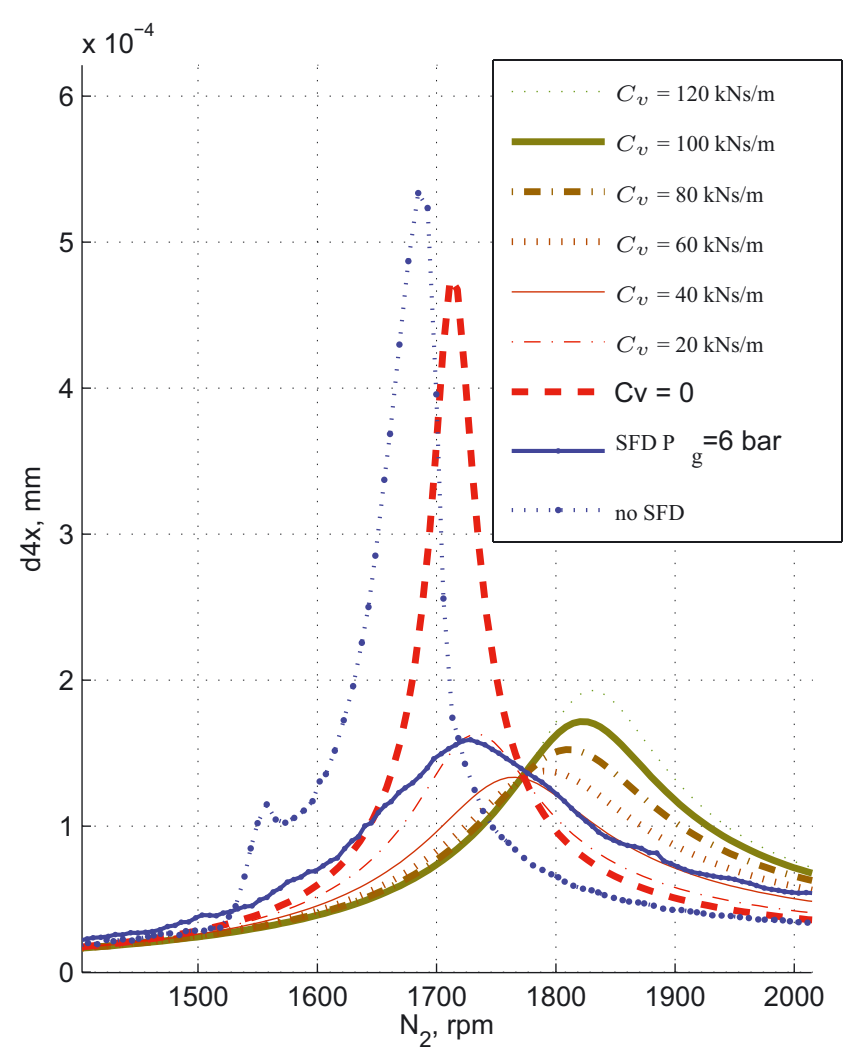

(a) mode 1

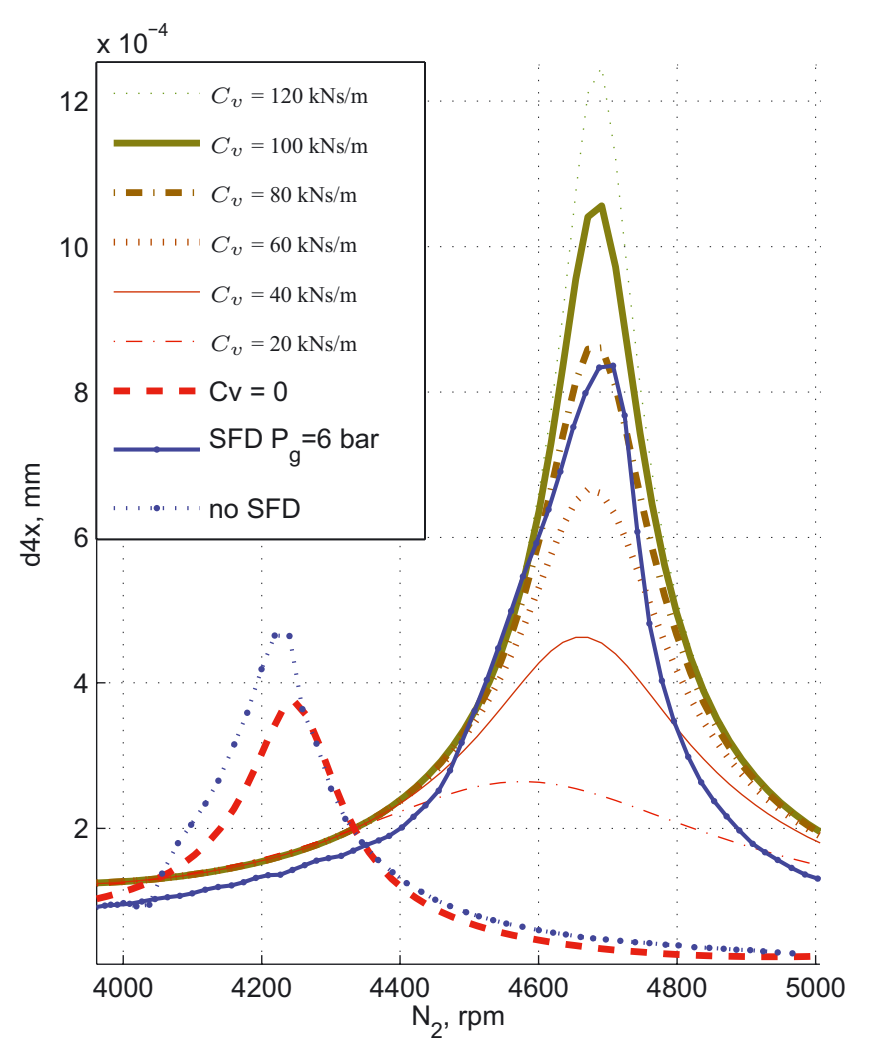

(b) mode 4

Fig. 6. Numerical and experimental unbalance response plot in view of estimation of apparent $C_{\mathrm{v}}$ at the middle of LP shaft. in the groove, with an amplitude of 1.5 bar (at sensor $\operatorname{Pr}_{1}$ ) in that case. Note that the shape of the pressure is different than in the first case and a spectral analysis would have shown that the signals contain more harmonics of HP rotor than in the first case. This shows the importance of the frequency span of the pressure sensors as $e$ increases in order to catch most of the spectral content. Considering the axial pressure distribution, sensors $\mathrm{Pr}_{2}$ and $\operatorname{Pr}_{5}$ have the highest levels, $\operatorname{Pr}_{3}, \operatorname{Pr}_{6}$ have intermediate levels and $\mathrm{Pr}_{4}$ has lower levels, which is consistent with the parabolic axial pressure shape of a short SFD.

Once these checks insuring the measured data consistency have been carried out, a more quantitative analysis is performed using a numerical model which is presented below.

\subsection{Simulation of the pressure in the film land}

A physical model which was used for the SFD design [12] is employed for analyzing the measurements. Further, this one will be used to estimate the SFD forces by interpolating the measured dynamic pressure over the whole film land, integrating. The estimated damping coefficient can then be estimated and compared to those identified in the overall dynamic study. The SFD model is based on the well known Reynolds equation with the short length bearing approximation [2]. It is generally admitted $[2,3]$ that the short bearing assumption, that is neglecting the circumferantial flow in the SFD, is valid for an open ended SFD with $L / 2 R \leq 0.25$. In our case, we should consider that we have $L / 2 R \approx 0.28$ which is about the required condition. Further, a check performed by means of the bidimentionnal Reynolds equation [3] (without the groove) solved by the finite difference method have shown that the short length assumption itself leads in our case to an over-estimation of about $3 \%$ to $4 \%$ (increasing with $\epsilon$ ) on the SFD tangential force.

Also, note that the use of the short length bearing approximation seems reasonable since the oil of the SFD land is discharged in a relatively deep groove $\left(C_{\mathrm{g}} / C=\right.$ 15) at $z=L$ (while it isn't the case at $z=0$ where the end is pratically closed by the ring seal). One can notice that the assumptions on the boundary conditions agree with the recorded pressure oscillation magnitudes alongside the sensors distribution: the dynamic pressure decreases from the seal ( see $\operatorname{Pr}_{2}, \operatorname{Pr}_{5}$ near $z=0$ ) to the groove (see $\operatorname{Pr}_{4}$ near $z=L$ ). Moreover, this axial variation is more than 5 times stronger than the circumferential one. The flow through the piston rings will be neglected as justified before and with the assumption for no cavitation the pressure inside the film land will be given by:

$$
p(\theta, z)=\frac{6 \mu}{h^{3}} \frac{\partial h}{\partial t}\left(z^{2}-L^{2}\right)+p_{\mathrm{g}}(\theta)
$$

where $\theta$ is the circumferential coordinate as shown in Figure 4 with its origin at the line joining the centers of the bearing and of the journal, $\mu$ the dynamic viscosity, $p_{\mathrm{g}}$ is the pressure in the groove limiting the film land at $z=L$, 


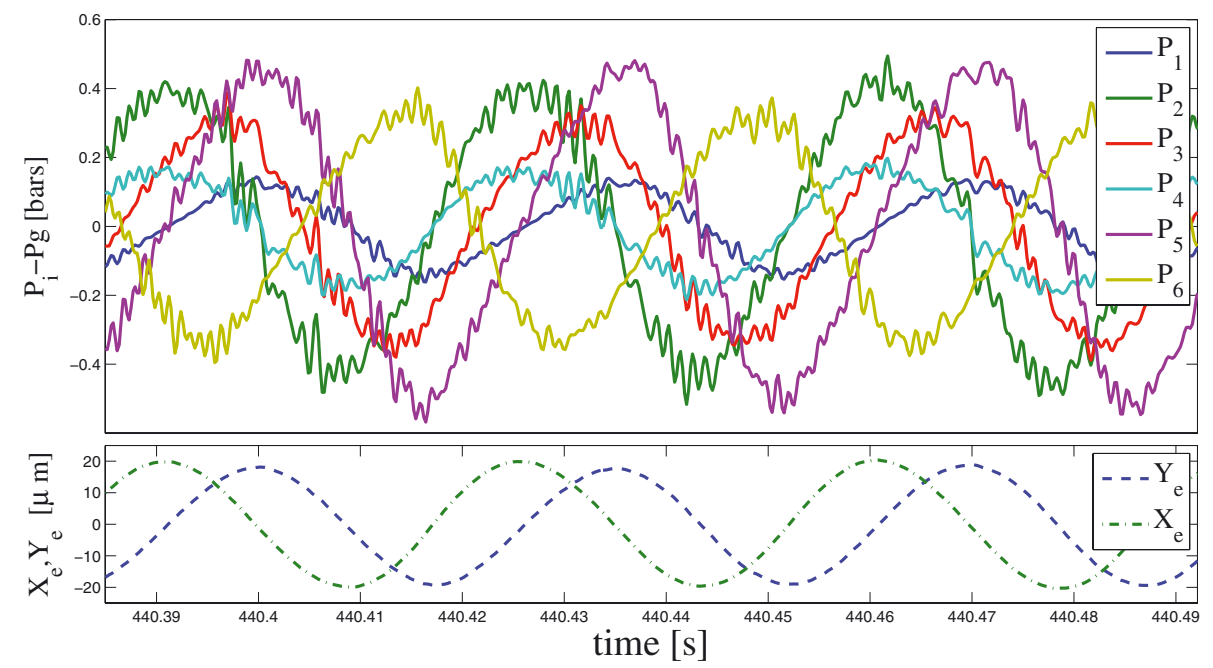

Fig. 7. Measurements in the SFD at the 1st critical speed-dynamic pressure and displacements.

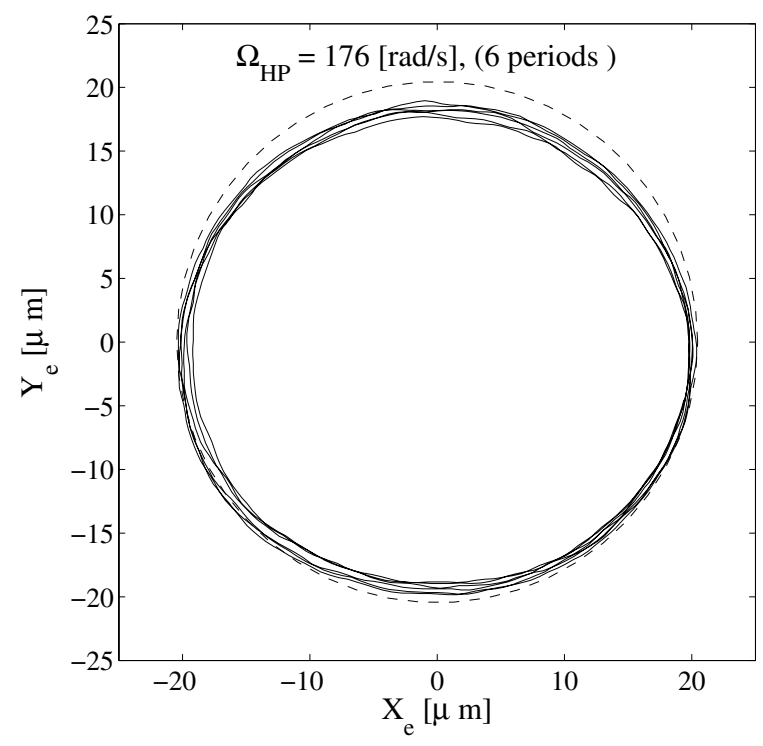

Fig. 8. Journal orbit at the 1st critical speed.

$h=C(1+\varepsilon \cos \theta)$ the film local thickness which can be obtained alternately using the displacements of the journal centre, at the particular sensors locations by:

$$
h\left(\hat{\theta}_{i}\right)=C+X_{e} \cos \hat{\theta}_{i}+Y_{e} \sin \hat{\theta}_{i} \quad i=1, \ldots, 6
$$

where $\hat{\theta}_{i}$ are the circumferential coordinates of the pressure sensors $\operatorname{Pr}_{i}(i=1, \ldots, 6)$. It is assumed that the film thickness is constant over the axial coordinate $Z$. Note that the influence of the supply mecanism in the groove which would have added a term linearly varying with distance from the groove in (3) is neglected given the very small flow through the ring seals at the end of the SFD.

The local squeezing rate at a particular sensor location is given by:

$$
\frac{\partial h}{\partial t}=\dot{X}_{e} \cos \hat{\theta}_{i}+\dot{Y}_{e} \sin \hat{\theta}_{i}
$$

expressed by means of the journal centre velocity components in the global frame $(\mathrm{O} ; X, Y, Z)$.

Recall that the inputs of the model are the known geometric parameters $\left(D, L, C, C_{\mathrm{g}}, L_{\mathrm{g}}\right)$, the oil dynamic viscosity $(\mu)$ which is obtained from the known relation $\mu(T)$ given for the class of viscosity of the oil used and the temperature which is measured during the test. A value of $T=29{ }^{\circ} \mathrm{C}$, measured during the run, was used in the present study. The velocity of the journal centre is obtained by numerical signal processing of the measured displacements in order to compute Equation (4).

Finally, the so-called simulated pressures at the $i$ th location will be obtained by:

$$
p_{i}(t)=p\left(\hat{\theta}_{i}-\phi(t), Z_{i}\right)
$$

where

$$
\phi=\arg \left(X_{e}(t)+\mathrm{i} Y_{e}(t)\right)
$$

is the attitude angle of the journal (with i the imaginary number) and $Z_{i}$ the axial coordinate of the pressure sensor.

Given Equations (1)-(4) and the measured displacement together with all needed parameters, the pressure at locations Pr $i$ will be simulated and then compared to measured ones $P_{i}(t)$ in the film land.

\subsection{Representation of the pressure oscillations in the groove}

The pressure in the groove will be taken into account in the simplest way by means of a model derived from the Hagen-Poiseuille law [15]:

$$
-\frac{1}{R} \frac{\partial p_{\mathrm{g}}}{\partial \theta}=\frac{128 \mu}{\pi D_{\mathrm{H}}^{4}} Q_{\mathrm{g}}
$$

where $p_{\mathrm{g}}$ is the pressure at a given angular position $\theta$ in the groove, $D_{\mathrm{H}}$ is the hydraulic diameter:

$$
D_{\mathrm{H}}=2 \gamma \frac{C_{\mathrm{g}} L_{\mathrm{g}}}{C_{\mathrm{g}}+L_{\mathrm{g}}}
$$




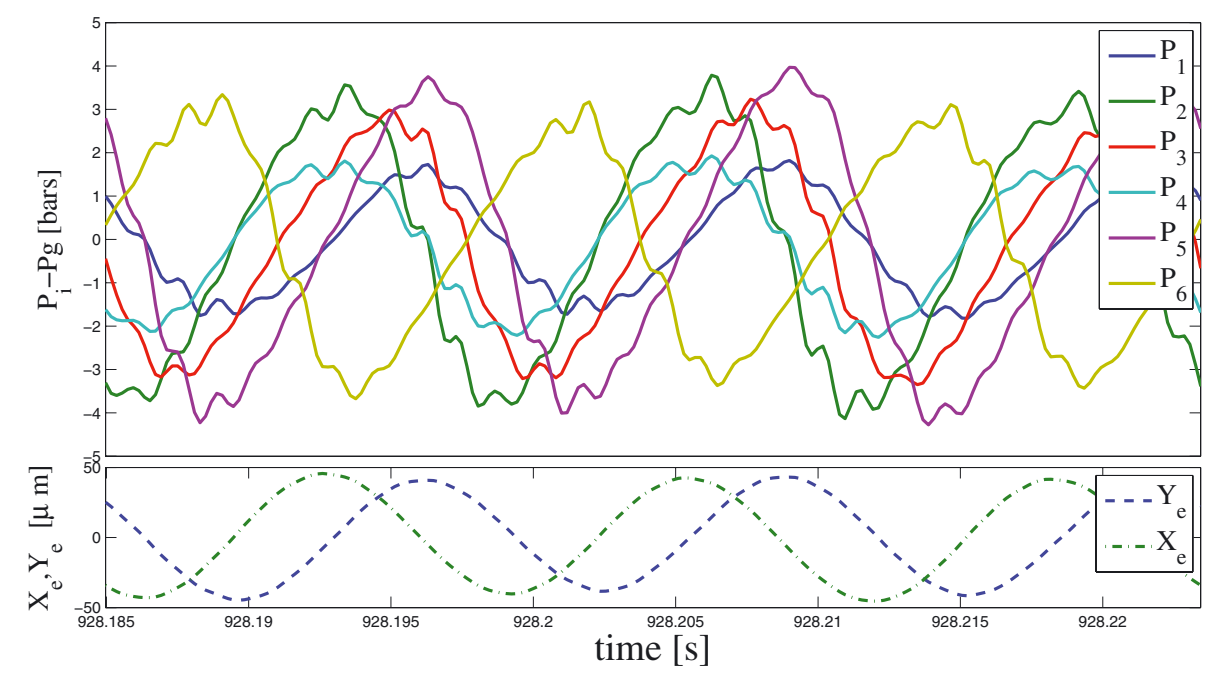

Fig. 9. Measurements in the SFD at the 4 th critical speed-dynamic pressure and displacements.

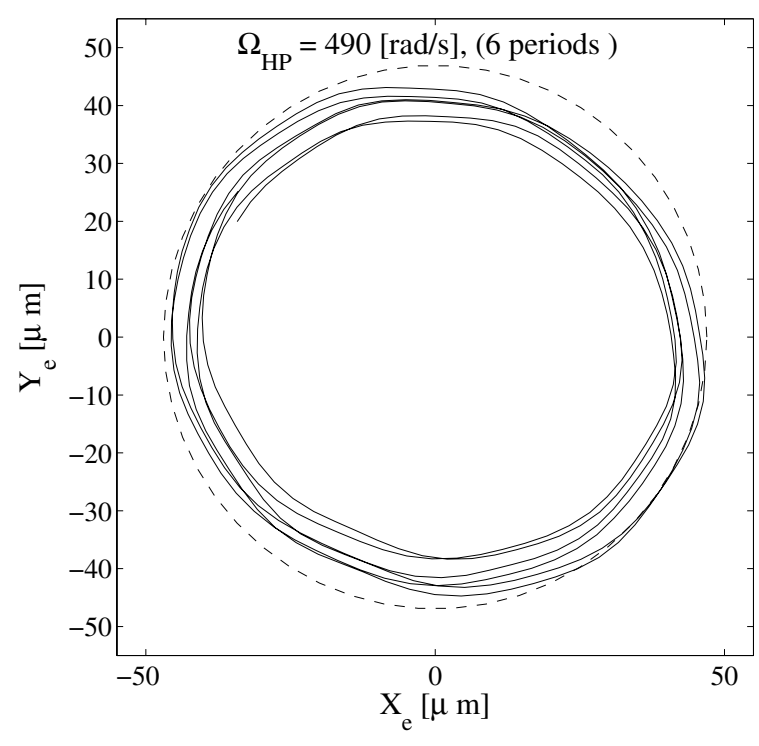

Fig. 10. Journal orbit at the 4 th critical speed.

where $\gamma$ is an updating parameter which will be used to match with the experimental data and $Q_{\mathrm{g}}$ is the circumferential flow rate in the groove. The squeezing effect in the groove is neglected given that $e / C_{\mathrm{g}} \ll 1$ in our case. More advanced models for feeding grooves can be found in $[13,14]$ taking into account a more complex description of the flow and inertia effect.

The local mass balance between the film land and the groove is expressed as follows:

$$
Q_{\mathrm{g}}(\theta+\mathrm{d} \theta)-Q_{\mathrm{g}}(\theta)+q_{1}(\theta) R \mathrm{~d} \theta=0
$$

where $q_{1}$ is the flow at the output of the SFD which is in fact forced to the groove given the film land model and which is given by:

$$
q_{1}(\theta, z=L)=L \frac{\partial h}{\partial t}(\theta)
$$

By integrating Equation (7) and using Equations (9) and (10) and taking into account the condition of periodicity around the circumference, the pressure in the groove is obtained by:

$$
p_{\mathrm{g}}(\theta)=\frac{128 \mu L R^{2}}{\pi D_{\mathrm{H}}^{4}}(\dot{e}(1-\cos \theta)-e \dot{\phi} \sin \theta)+P_{\mathrm{g}}
$$

\subsection{Comparison of measured and simulated pressures in SFD}

Figure 11 shows the direct comparison of simulated $\left(p_{i}(t)\right)$ and measured $\left(P_{i}(t)\right)$ time history of pressure for the case of the 1st critical speed over 6 periods of revolution of the HP rotor (a normalized time $t / \tau_{\mathrm{HP}}$ is used). A rather fair correlation can be noticed in the film land and in the groove despite the simplicity of the model and of the determination of the input parameters (taking the nominal viscosity law and the measured temperature on the bearing). Only $\gamma$ needed to be updated to 0.85 (from its nominal value $\gamma=1$ ) in order to fit the pressure in the groove. Also, one could note that the amplitudes of oscillations of pressure at higher frequency are reproduced. Some discrepancies can be noted at station $\mathrm{Pr}_{4}$ where the level is very low and at $\operatorname{Pr}_{6}$.

A similar comparison is drawn for the case of the 4 th critical speed and is shown in Figure 12 where it can be found that the correlation is very satisfactory too for $\mathrm{Pr}_{1}$, $\mathrm{Pr}_{2}, \mathrm{Pr}_{3}, \mathrm{Pr}_{5}$ but that some discrepancies are noticed for $\mathrm{Pr}_{4}$ and $\mathrm{Pr}_{6}$. The matching for the pressure inside the groove is not as good as in the first case. The correcting factor is set to $\gamma=0.7$ (different from the first case) to match the amplitude of the pressure but a slight phase lag is seen which cannot be caught by the model.

\subsection{Estimation of the SFD forces}

The resulting force generated by the squeezing effect in the half-short uncavitated SFD is deduced from the 

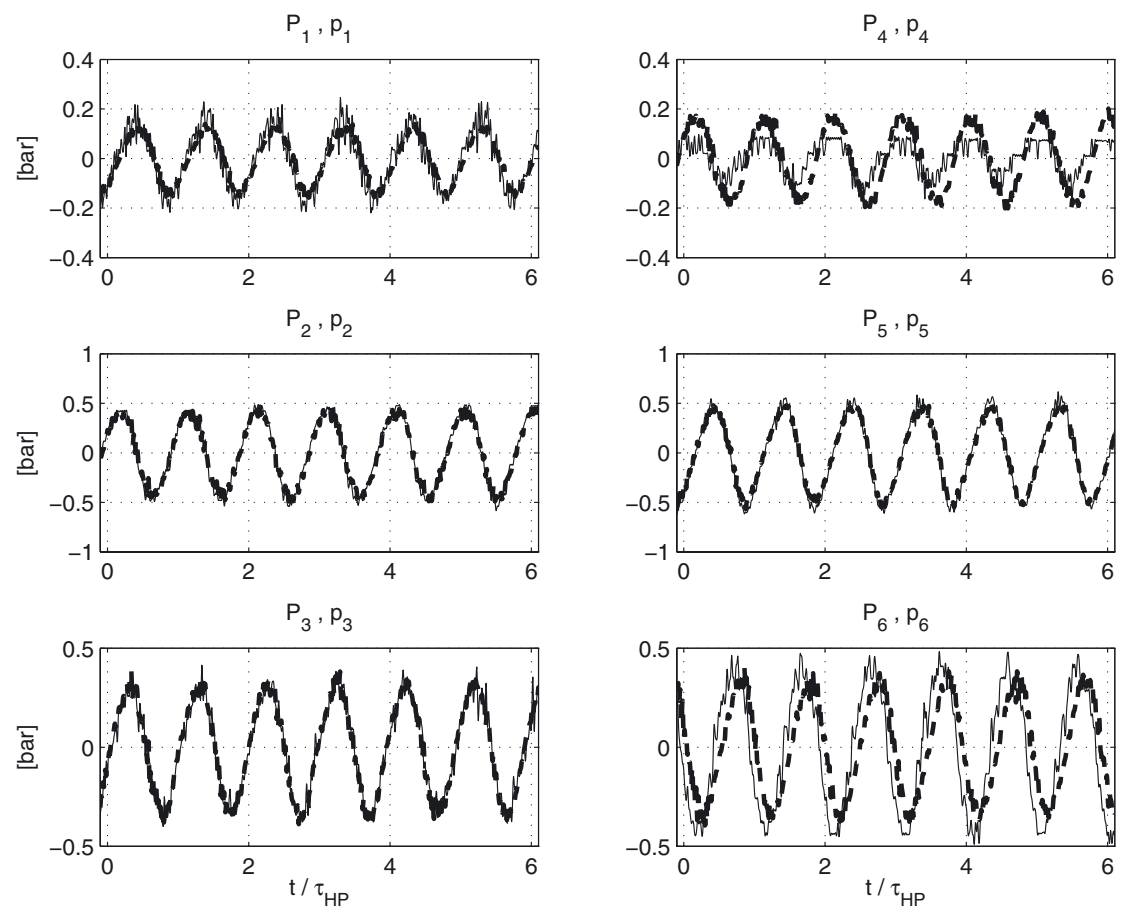

Fig. 11. Measured (solid line) and simulated (dashed line) dynamic pressure at 1st critical speed.
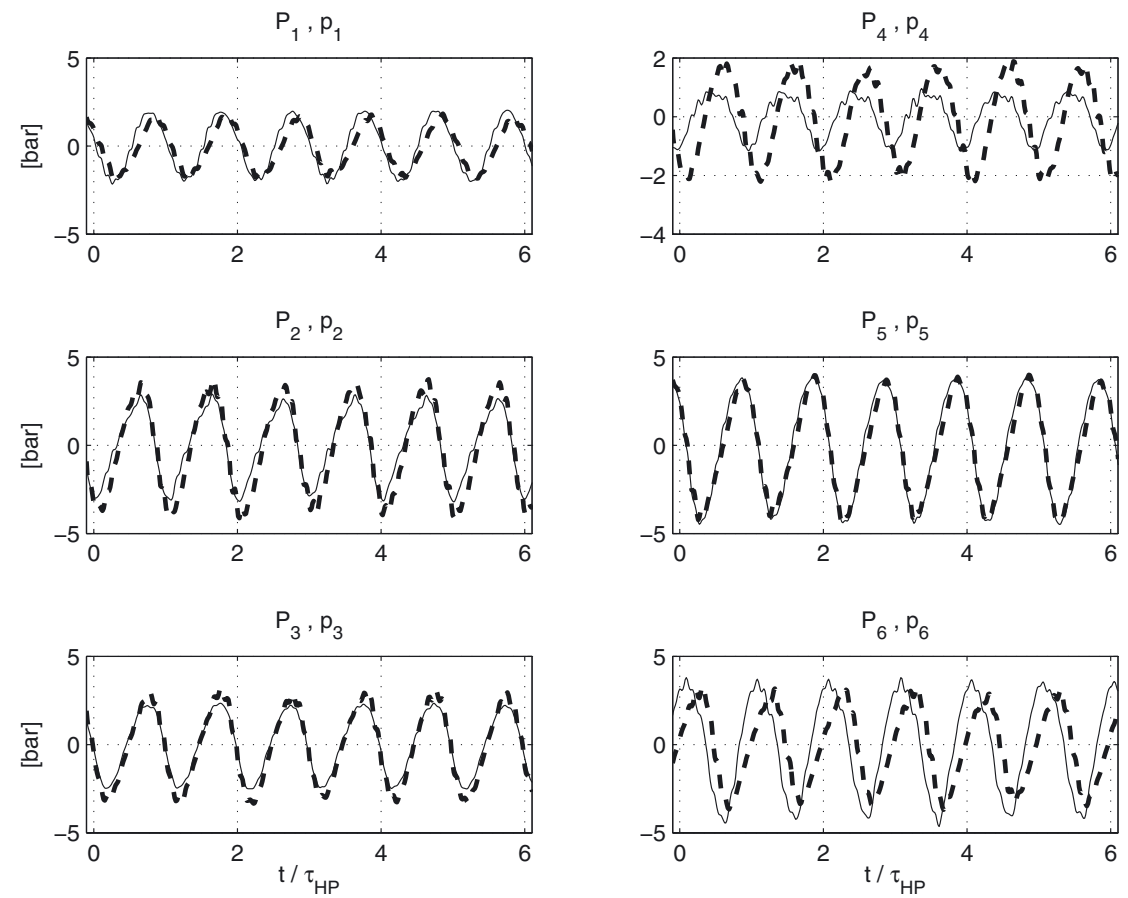

Fig. 12. Measured (solid line) versus simulated dynamic pressure (dashed line) at 4th critical speed.

classical analytical solution for the short bearing [2]:

$$
\begin{aligned}
& f_{\mathrm{r}}=-\frac{4 \mu R L^{3}}{C^{3}} \frac{\pi\left(1+2 \varepsilon^{2}\right)}{\left(1-\varepsilon^{2}\right)^{5 / 2}} \dot{e} \\
& f_{\mathrm{t}}=-\frac{4 \mu R L^{3}}{C^{3}} \frac{\pi}{\left(1-\varepsilon^{2}\right)^{3 / 2}} \dot{\phi}
\end{aligned}
$$

where $f_{\mathrm{r}}$ and $f_{\mathrm{t}}$ are the radial and tangential components of the resulting force from the film land along the radial and tangential directions respectively as shown in Figure 4. The non-linear nature of the SFD is reflected by terms figuring in the fraction in Equations (12) and (13) including the variable $\varepsilon$ which in our case represents about $3 \%$ of relative difference between tangential forces and $10 \%$ for radial forces if orbits with $\varepsilon=0.08$ and $\varepsilon=0.16$ 

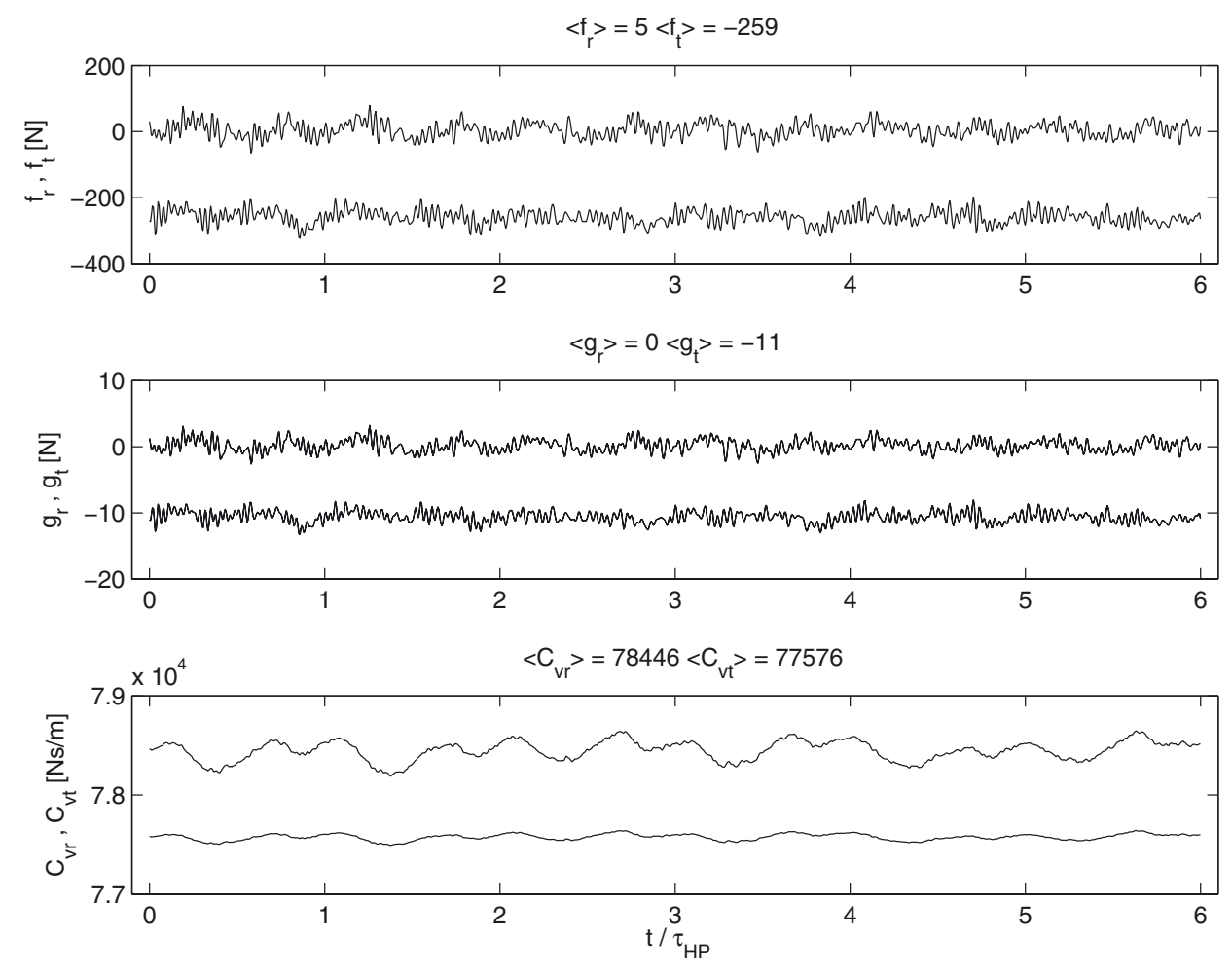

Fig. 13. Estimation of SFD force and damping coefficient at 1st critical speed.

are compared. This can be considered as a slight nonlinear effect.

The contribution of the groove is computed in the same way as for the SFD, by integrating over the circumference leading to the analytical forms:

$$
\begin{aligned}
& g_{\mathrm{r}}=\int_{0}^{L_{\mathrm{g}}} \int_{0}^{2 \pi} p_{\mathrm{g}}(\theta) \cos (\theta) \mathrm{d} z R \mathrm{~d} \theta=-\frac{128 \mu R^{3} L L_{\mathrm{g}}}{D_{\mathrm{H}}^{4}} \dot{e} \\
& g_{\mathrm{t}}=\int_{0}^{L_{\mathrm{g}}} \int_{0}^{2 \pi} p_{\mathrm{g}}(\theta) \sin (\theta) \mathrm{d} z R \mathrm{~d} \theta=-\frac{128 \mu R^{3} L L_{\mathrm{g}}}{D_{\mathrm{H}}^{4}} e \dot{\phi}
\end{aligned}
$$

where $g_{\mathrm{t}}$, and $g_{\mathrm{r}}$ are the radial and tangential components of the resulting force produced by the groove.

The contribution of the groove pressure is added to the one resulting from the film land in order to compute the net force produced by the damper. From Equations (12)-(15) relating forces to velocity components, so-called experimental instantaneous damping coefficients are estimated as follows:

$$
C_{\mathrm{vr}}(t)=\frac{f_{\mathrm{r}}+g_{\mathrm{r}}}{\dot{e}} \quad C_{\mathrm{vt}}(t)=\frac{f_{\mathrm{t}}+g_{\mathrm{t}}}{e \dot{\phi}}
$$

where $C_{\mathrm{vr}}$ and $C_{\mathrm{vt}}$ are computed by means of the radial and respectively tangential components of the velocity deduced from the measurements:

$$
\dot{e}=\dot{X}_{e} \cos \phi+\dot{Y}_{e} \sin \phi \quad e \dot{\phi}=-\dot{X}_{e} \sin \phi+\dot{Y}_{e} \cos \phi
$$

and of the SFD forces at instant times for which Equations (16) aren't singular. Figures 13 and 14 show the
SFD forces $f_{\mathrm{t}}, f_{\mathrm{r}}$, the groove forces $g_{\mathrm{t}}, g_{\mathrm{r}}$ as well as the associated damping coefficients $C_{\mathrm{vt}}$ and $C_{\mathrm{vr}}$ obtained in this way for the 1 st and 4 th critical speeds. Mean values are taken over the shown 6 periods and are indicated between brackets in the diagrams. Results obtained for the 4th critical speed are found in Figures 14.

As orbits are close to circular one it is convenient to use the radial and tangential coordinates for the interpretation of SFD forces. In both cases, the radial components have a mean value which is close to zero with some oscillations also reflected on the damping coefficients. In particular, a frequency component twice the HP rotor frequency is observed which is probably associated to the ellipticity of the trajectory more perceptible on the radial component (see $C_{\mathrm{vr}}$ ). A perfect centered circular orbit for an uncavitated axisymmetric SFD following the Reynolds equation would have given a zero radial force. Consistent values are found for $C_{\mathrm{vt}}$ and $C_{\mathrm{vr}}$ the latter being smaller according to Equations (12), (13) where exponents are different $(5 / 2$ and $3 / 2)$.

When comparing the results from the two critical speeds, the damping coefficients are higher for the 4th one. This is consistent with the non-linear dependance on $\varepsilon$ discussed above although this can explain at most 3 percent of the difference between these estimates as mentioned. The formulated model was able to explain the observed SFD pressure data to a precision satisfactory for engineering application and damping factor in two cases with different kinematic conditions. As the matching between the model and the experimental pressure data is better in the first case, the resulting identification of $C_{\mathrm{vt}}$ is probably more accurate whereas more uncertainties 

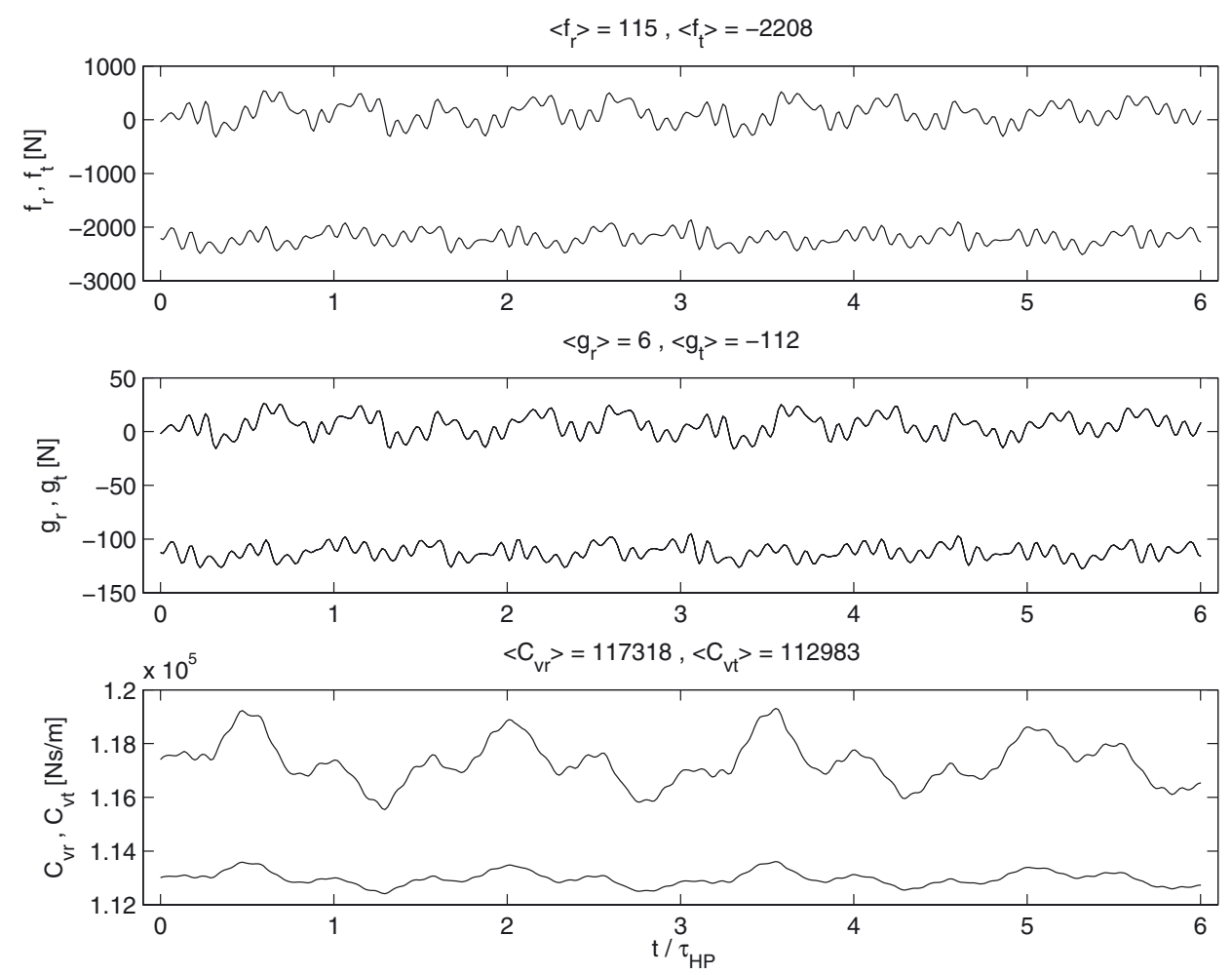

Fig. 14. Estimation of SFD force and damping coefficient at 4th critical speed.

should be considered for the second case. In particular, discrepancies have been noticed in term of amplitude and phase on some of the $\operatorname{Pr}_{i}$.

Misalignment between the journal and the outer ring due to imperfection in the initial centering process is a possible direction of investigation which could explain some discrepancies between model and experience pressure responses although the actual kinematic is taken into account in the model. Misalignment may impact significantly the local film thickness $(h)$ especially when the eccentricity ratio gets higher. Also inertia effect could be considered. As referred by [14], inertia effect can explain phase shift of dynamic pressure compared to inertia-less ones leading to centrifugal force. Further, inertia effect can have an effect on the negative part of the dynamic pressure resulting in an increase of the tangential force. A more accurate identification of the SFD characteristics could therefore be obtained by taking into account these two phenomena. The influence of some other phenomena such that the local flow through the split of the seal ring as in [16] or the hydraulic coupling between the SFD and the feeding system can be taken into account as in [3].

\section{Synthesis and discussion}

A synthesis of the identified damping characteristics values from the two approaches, namely the overall dynamic and the SFD studies is addressed in this section.

First is to say that the results of the SFD study are in good agreement with the rotor dynamic with a relative difference of about $25 \%$ between the two approaches on the estimated parameter $C_{\mathrm{v}}$. Considering the $C_{\mathrm{vt}}$ 's, the identified numerical values for these damping factors are on the order of $77000 \mathrm{Nm} . \mathrm{s}^{-1}$ for the 1st critical speed and of $113000 \mathrm{Nm} . \mathrm{s}^{-1}$ for the 4 th one and should be compared to those found in the overall dynamic study which are respectively $60000 \mathrm{Nm} . \mathrm{s}^{-1}$ and $90000 \mathrm{Nm} . \mathrm{s}^{-1}$. These latters are able to reproduce the frequency shift and amplitudes observed during the rotor experiments at the two modes frequencies.

These values are different from Reference [12] (respectively 50000 and 130000 Nm.s ${ }^{-1}$ ) because the model used herein has been updated since. This illustrates how the identification of the parameter is sensible to errors in the overall dynamic model and this specially for the 4 th mode which point was adressed in the conclusion of [12]. In both cases, the equivalent damping coefficient is greater for the 4th critical speed which makes even consistant the two kinds of results. Although, the $C_{\mathrm{v}}$ from the SFD approach seems to be overestimated for the two critical speeds.

One possible main reason, is that the pressure calculated in the groove is added (see Eq. (2)) and therefore integrated over the film land. It is possible that the resulting force is in this way overestimated. If the pressure of the groove wasn't summed in the SFD land and the experimental pressure fitted again, then the damping coefficients would be lower $\left(50000\right.$ and $70000 \mathrm{Nm} . \mathrm{s}^{-1}$ respectively for the two modes considered). Although, the pressure field in this case wouldn't be no more continuous. This may suggest that the model for the groove and its interaction with the film land should be improved to be more realistic and to find a more accurate estimate. 
Nevertheless, these different estimated values seem to reduce the possibility of a significative interfering force such that was suspected in [12]. The suggestion was that, discrepancies between results coming from the two approaches could indicate that some interfering forces are not taken into the model of the SFD which are present during the test and after identified in the rotor study [12]. For instance, possible friction between the two rings of the SFD and with seal rings being pressed against the wall of their groove by film land pressure could result in a dissipation force. Also, although the short bearing model was able to fit the experimental data very fairly, its underlying assumptions may introduce an error in the estimation of the damping coefficient.

Misalignement, inertia effect, groove-SFD model have been discussed above as possible improvements for force identifications with the SFD model. Further improvement in the rotor dynamic study can also be considered. For instance, possible centrifugal forces due to inertia effect identified with an improved SFD model could be introduced in the rotor model and identified as well as for viscous damping forces.

\section{Conclusion}

Numerical and experimental studies of a SFD mounted on a dual shaft test rig have allowed to validate a Reynolds-based model of the SFD flow with the feeding groove contribution taken into account. These models prove to be quite representative, to the point of yielding a viscous damping coefficient in agreement with that issued from the overall dynamic consideration. In spite of its simplicity, the used SFD model is able to explain the observed SFD dynamic pressure in the fluid and to provide a satisfactory estimate of the damping factor at two critical speeds corresponding to different kinematic conditions of eccentricity and speed.

Acknowledgements. This work is supported by the Direction générale de la compétitivité, de l'industrie et des services (Dgcis) - Ministère de l'Économie, des Finances et de l'Industrie in the framework of the CALME project - 082 906347 .

\section{References}

[1] J.M. Vance, Rotordynamics in turbomachinery, John Wiley \& Sons, 1988

[2] D. Childs, Turbomachinery rotordynamics. Phenomena, modelling and analysis, Wiley Interscience, 1993
[3] F. Assis Rodrigues, Étude de la dynamique non-linéaire d'amortisseurs du type squeeze film, Ph.D. thesis, École Centrale de Lyon, 2003

[4] C. Defaye, Intégration numérique et expérimentale d'éléments amortisseurs de type squeeze film damper dans les moteurs d'avion, Ph.D. thesis, Université de Poitiers, 2006

[5] F. Assis Rodrigues, F. Thouverez, C. Gibert, L. Jezequel, Chebyshev polynomials fits for efficient analysis of finite length squeeze film damped rotors, J. Eng. Gas Turbine Power 125 (2003) 175-183

[6] F.Y. Zeidan, L. San Andres, J.M. Vance, Design and aplication of squeeze film dampers in rotating machinery, Proceedings of the twenty-fifth turbomachinery symposium, Texas A\&M University, 1996, pp. 169-188

[7] A. El-Shafei, Stability analysis of intershaft squeeze film dampers, J. Sound Vibr. 148 (1991) 395-408

[8] K. Gupta, S. Chatterjee, Dynamics of an improved inter shaft squeeze film damper: theory and experiment, Proceedings of GT2007 ASME Turbo Expo 2007: Power for Land, Sea and Air, May 14-17, 2007, Montreal, Canada, (GT-27534):10, 2007

[9] A. Delgado, L. San Andres, Identification of squeeze-film damper force coefficients from multiple-frequency, noncircular journal motions, Proc. GT2009 ASME Turbo Expo 2009: Power for Land, Sea and Air, June 8-12, 2009, Orlando, Florida, USA (GT2009-59175):10, 2009

[10] M. Guskov, J.-J. Sinou, F. Thouverez, O. Naraikin, Experimental and numerical investigations of a dualshaft test rig with intershaft bearing, Int. J. Rotat. Mach. (2007), in press

[11] M. Guskov, Dynamique non-linéaire des systèmes multirotors, Études numérique et expérimentale, Ph.D. thesis, Ecole Centrale de Lyon, 2007

[12] M. Guskov, C. Gibert, L. Sanchez, F. Thouverez, Réponse dynamique d'un banc d'essais bi-rotors équipé d'un amortisseur squeeze-film : études numérique et expérimentale, XIX ${ }^{\mathrm{e}}$ Congrès Francais de mécanique, 2009

[13] Tan Qingchang, Chang Ying, Wang Lyjiang, Effect of a circumferential feeding groove on fluid force in short squeeze film dampers, Trib. Int. 30 (1997) 409-416

[14] S.Y. Jung, L.A. San Andres, J.M. Vance, Measurements of pressure distributions and force coefficients in a squeeze film damper. Part ii: Partially sealed configuration, Trib. Trans. 34 (1991) 383-388

[15] I.E. Idel'Cik, Memento des Pertes de Charge, Eyrolles Editeur, 1969

[16] M. Arghir, J. Frene, Static and dynamic analysis of annular seals, in Proc. of ASME Fluids Engineering Division Summer Meeting 2006, FEDSM2006, Vol. 2 Forums, 2006, pp. 517-526 